6 Dannaeus A, Inganaes M. A follow-up study of children with food allergy Clinical course in relation to serum IgE and IgG antibody levels to milk, egg and fish. Clin Allergy 1981;11:533-9.

7 Host A, Halken S, Jacobsen HP, Estmann A, Mortensen S, Mygil S. The natural course of cow's milk protein allergy/intolerance (abstract). $J$ Allergy Clin Immunol 1997;99(1, pt 2):S491.

8 Bock SA, Sampson HA, Atkins FM, Zeiger RS, Lehrer S, Sachs M, et al. Double-blind, placebo-controlled food challenge (DBPCFC) as an office procedure: a manual. J Allergy Clin Immunol 1988;82:986-97.

9 Hamilos DL, Oppenheimer JJ, Nelson HS, Wenzel S, Driscoll S, Lockey $\mathrm{RF}$, et al. Suggested approaches for research protocols involving the potential for life-threatening reactions. J Allergy Clin Immunol 1993; 92:1101-20.

10 Sampson HA, Ho DG. Relationship between food-specific IgE concentrations and the risk of positive food challenges in children and adolescents. J Allergy Clin Immunol 1997;100:444-51.

11 Tariq SM, Stevens M, Matthews S, Ridout S, Twiselton R, Hide DW. Cohort study of peanut and tree nut sensitisation by age of 4 years. $B M J$ 1996:313:514-7.

12 Sporik R, Hill D. Allergy to peanut, nuts, and sesame seed in Australian children (letter). BMJ 1996;313:1477-8.

13 Hourihane J O'B, Kilburn SA, Dean TP, Warner JO. Clinical characteristics of peanut allergy. Clin Exp Allergy 1997;27:634-9.

14 Cooke SK, Sampson HA. Allergenic properties of ovomucoid in man J Immunol 1997;159(4):2026-32.

15 Burks AW, Cockrell G, Stanley JS, Helm RM, Bannon GA. Recombinan peanut allergen Ara $\mathrm{h}$ I expression and IgE binding in patients with peanut hypersensitivity. J Clin Invest 1995;96:1715-21.

(Accepted 21 January 1998)

\title{
Science commentary: Why do some children grow out of peanut allergy?
}

One hypothesis which may explain why some children grow out of their peanut allergy lies in the physical structure of the peanut proteins. If the protein is visualised as a string of amino acid beads scrunched up into a 3-dimensional ball there are two ways an antibody can bind to that structure. Firstly, an antibody can bind to a specific antigen by attaching itself to sequential amino acid beads in the protein. These sections of the protein are known as linear epitopes. Alternatively, an antibody binds to a section which is effectively folded up so that it not only binds to a number of amino acid beads in one part of the protein string but also to beads in other sections of the string. These antigenic binding sites are known as conformational epitopes.

Research in other food allergies suggests that children who develop tolerance to peanuts may have pea- nut specific IgE which binds much more to conformational peanut epitopes (which are generally more labile and easily destroyed by heat) and that children who remain reactive to peanuts have $\operatorname{IgE}$ which binds mostly to linear epitopes (which are very stable). As the gut matures with age more linear epitopes than conformational epitopes pass through the gut wall. So if the hypothesis is found to be true this could explain why some people continue to react to peanuts and others seemingly outgrow their allergy.

Such differences in IgE binding have already been observed in children with egg or cows' milk allergy. An interesting question is why up to $50 \%$ of children with egg or cows' milk allergy outgrow the allergy while only about $10 \%$ seem to develop tolerance to peanuts. Abi Berger, science editor, BMJ

\section{Effectiveness of antibiotic prophylaxis in critically ill adult patients: systematic review of randomised controlled trials}

\author{
Roberto D’Amico, Silvia Pifferi, Cinzia Leonetti, Valter Torri, Angelo Tinazzi, Alessandro Liberati on
} behalf of the study investigators

\begin{abstract}
Objective: To determine whether antibiotic prophylaxis reduces respiratory tract infections and overall mortality in unselected critically ill adult patients.

Design: Meta-analysis of randomised controlled trials from 1984 and 1996 that compared different forms of antibiotic prophylaxis used to reduce respiratory tract infections and mortality with aggregate data and, in a subset of trials, data from individual patients.

Subjects: Unselected critically ill adult patients; 5727 patients for aggregate data meta-analysis, 4343 for confirmatory meta-analysis with data from individual patients.

Main outcome measures: Respiratory tract infections and total mortality.

Results: Two categories of eligible trials were defined: topical plus systemic antibiotics versus no treatment and topical preparation with or without a systemic antibiotic versus a systemic agent or placebo. Estimates from aggregate data meta-analysis of
\end{abstract}

16 trials (3361 patients) that tested combined treatment indicated a strong significant reduction in infection (odds ratio $0.35 ; 95 \%$ confidence interval 0.29 to 0.41$)$ and total mortality $(0.80 ; 0.69$ to 0.93$)$. With this treatment five and 23 patients would need to be treated to prevent one infection and one death, respectively. Similar analysis of 17 trials (2366 patients) that tested only topical antibiotics indicated a clear reduction in infection $(0.56 ; 0.46$ to 0.68$)$ without a significant effect on total mortality (1.01; 0.84 to 1.22). Analysis of data from individual patients yielded similar results. No significant differences in treatment effect by major subgroups of patients emerged from the analyses.

Conclusions: This meta-analysis of 15 years of clinical research suggests that antibiotic prophylaxis with a combination of topical and systemic drugs can reduce respiratory tract infections and overall mortality in critically ill patients. This effect is significant and worth while, and it should be considered when practice guidelines are defined.
Valter Torri, chief of biometry unit Angelo Tinazzi, computer scientist Alessandro Liberati, head

Maggiore Ospedale IRCCS, 20122

Milan

Silvia Pifferi,

research fellow

Cinzia Leonetti, research fellow

continued over

BMJ 1998;316:1275-85 

Dr A Liberati, Italian Cochrane Centre, Laboratory of Health Services Research, Mario Negri Institute, Via Eritrea 62, 20157 Milan, Italy

Cochrane@irfmn. mnegri.it
Correspondence to:

\section{Introduction}

Nosocomial infections, especially pneumonia, are an important cause of morbidity and mortality in critically ill patients. The incidence of pneumonia in such patients ranges between $7 \%$ and $40 \%$, and the crude mortality from ventilator associated pneumonia (VAP) may exceed $50 \%$. Although not all deaths in patients with this form of pneumonia are directly attributable to infection, it has been shown to contribute to mortality in intensive care units independently of other factors that are also strongly associated with such deaths. ${ }^{1}$ In a case-control study of ventilated patients an increase in mortality of $27 \%$ was attributable to ventilator associated pneumonia. ${ }^{2}$ Considerable efforts have been made to develop and evaluate methods for reducing respiratory infections. One strategy involves the use of selective decontamination of the digestive tract (SDD). Different decontamination protocols have been used in different trials, and investigators often disagree on its most appropriate definition. Traditionally, selective decontamination of the digestive tract indicates a method designed to prevent infection by eradicating and preventing carriage of potentially pathogenic aerobic microorganisms from the oropharynx, stomach, and gut. It consists of antibiotics applied topically to the oropharynx and through a nasogastric tube. In many trials treatment with systemic antibiotics has been added in the first days after patients are admitted to prevent "early" infections.

A decontamination regimen based on oral non-absorbable antibiotics was first used in 1984 by Stoutenbeek et al in a group of patients with multiple trauma. ${ }^{3}$ The incidence of nosocomial infections was reduced from $81 \%$ to $16 \%$ in a non-randomised comparison with a historical control group. Further studies tested the efficacy of decontamination in patients in intensive care with morbidity related to infection as the main end point. The results showed that decontamination reduced infection, but it was not clear whether there was a reduction in mortality.

Between 1991 and 1995 five different metaanalyses on the effect of antibiotic prophylaxis on

Table 1 Results of five published meta-analyses of randomised controlled trials on antibiotic prophylaxis for mortality and respiratory tract infection in patients in intensive care

\begin{tabular}{|c|c|c|c|}
\hline \multirow[b]{2}{*}{ End points } & \multicolumn{3}{|c|}{ Point estimates $(95 \% \mathrm{Cl})$} \\
\hline & All trials & $\begin{array}{c}\text { Topical plus systemic } \\
\text { antibiotics }\end{array}$ & $\begin{array}{l}\text { Topical antibiotics } \\
\text { alone }\end{array}$ \\
\hline \multicolumn{4}{|c|}{ Vandenbroucke-Grauls et al ${ }^{4}$ ( 6 trials, 491 patients) } \\
\hline Mortality & $0.70^{*}(0.45$ to 1.09$)$ & NA & NA \\
\hline Infection & $0.12^{\star}(0.08$ to 0.19$)$ & NA & NA \\
\hline \multicolumn{4}{|c|}{ SDD Trialists' Group ${ }^{5}$ (22 trials, 4142 patients) } \\
\hline Mortality & $0.90^{*}(0.79$ to 1.04$)$ & $0.80(0.67$ to 0.97$)$ & 1.07 (0.86 to 1.32$)$ \\
\hline Infection & $0.37^{\star}(0.31$ to 0.43$)$ & $0.33(0.27$ to 0.40$)$ & $0.43(0.33$ to 0.56$)$ \\
\hline \multicolumn{4}{|c|}{ Heyland et al ${ }^{6}$ (24 trials, 3312 patients) } \\
\hline Mortality & $0.87 \dagger(0.79$ to 0.97$)$ & 0.81 (0.71 to 0.95$)$ & $1.00(0.83$ to 1.19$)$ \\
\hline Pneumonia & $0.46 \dagger(0.39$ to 0.56$)$ & $0.48(0.39$ to 0.60$)$ & $0.43(0.32$ to 0.59$)$ \\
\hline \multicolumn{4}{|c|}{ Kollef et al ${ }^{8}$ (16 trials, 2270 patients) } \\
\hline Mortality & $0.02 \ddagger(-0.02$ to 0.05$)$ & NA & NA \\
\hline Pneumonia & $0.14 \ddagger(0.12$ to 0.17$)$ & NA & NA \\
\hline Tracheobronchitis & $0.05 \ddagger(0.02$ to 0.09$)$ & NA & NA \\
\hline \multicolumn{4}{|c|}{ Hurley et al ${ }^{7}$ (26 trials, 3768 patients) } \\
\hline Mortality & $0.86^{*}(0.74$ to 0.99$)$ & NA & NA \\
\hline Infection & $0.35^{\star}(0.30$ to 0.42$)$ & NA & NA \\
\hline
\end{tabular}

$\mathrm{NA}=$ data not in published articles. ${ }^{*}$ Odds ratio. †Relative risk. $¥$ Risk difference. infections and mortality were published. ${ }^{4-8}$ Their results are summarised in table 1 . All confirmed a significant reduction in infections, though the magnitude of the effect varied from one review to another. The estimated impact on overall mortality was less evident and generated considerable controversy on the cost effectiveness of the treatment. Only one among the five available reviews, however, suggested that a weak association between respiratory tract infections and mortality and lack of sufficient statistical power may have accounted for the limited effect on mortality. ${ }^{5}$ The authors suggested that, given the baseline risk of death in the populations typically enrolled in existing trials, between 2000 and 3000 patients were probably needed to detect reliably a relative reduction in mortality in the $10 \%-20 \%$ range $^{5}$

We report here on an updated and refined meta-analysis made possible by the enthusiastic collaboration of most investigators in the topic. Besides updating the results by using data from randomised controlled trials published since the 1993 paper, ${ }^{5}$ there are two main differences between this and previously published meta-analyses. The first is the way trials have been grouped to test the effectiveness of the treatment. Contrary to previous practice we have separately analysed trials that tested combinations of topical and systemic antibiotics from trials that tested the effect of topical drugs alone. The second is that information for individual patients was sought from all trials. Results from this more refined type of meta-analysis, which proved feasible in $4343 / 5727(76 \%)$ patients, are reported and compared with findings from the corresponding aggregate datasets.

\section{Patients and methods}

\section{Search strategy}

We searched for randomised controlled trials published from January 1984 to December 1996. Studies were identified through Medline (MeSH keywords: "Intensive care units," "Critical care," "Antibiotic combined therapeutic use," "Antibiotics combined administration and dosage," "Respiratory tract infections prevention and control" with the keyword "SDD"). Other studies were evaluated because they were listed in previous meta-analyses. The organiser of the first European Consensus Conference on Intensive Care Medicine (held in December 1991) also provided a list of all investigators who had ever published on the topic. An additional search focused on proceedings of scientific meetings held on the subject and personal contacts were established with other known investigators. No formal inquiry was made through pharmaceutical companies.

\section{Eligibility criteria for studies}

All trials, published and unpublished, which tested the effect of antibiotic prophylaxis for the prevention of respiratory tract infections and deaths in unselected critically ill adult patients were considered. No language restriction was applied. Only randomised trials were accepted to guarantee control of selection bias. Studies that were determined on closer scrutiny not to be properly randomised (see definition below) were not included. 
Studies based on specific preselected types of patients (that is, patients undergoing elective oesophageal resection, cardiac or gastric surgery, and liver transplantation or suffering from acute liver failure) were excluded from this meta-analysis. Similarly, we excluded studies in which over half the patients did not undergo mechanical ventilation for more than 48 hours. Details on the reasons for exclusion are reported in the appendix..$^{9-18}$

We grouped eligible trials into two categories according to the type of antibiotic prophylaxis. The first group comprised studies in which a combination of systemic and topical antibiotics was compared with no prophylactic treatment. ${ }^{19-34}$ The second comprised studies in which topical antibiotics alone were tested. In this second category two types of trials were considered together-those in which topical antibiotics were tested against an untreated group (S Jacobs, M Zuleika, personal communication) $)^{35-44}$ and those in which the combination of topical plus a systemic drug was compared with a protocol based on a systemic antibiotic agent only. ${ }^{45-50}$ Any combination of topical or systemic antibiotic (that is, type of drugs) was accepted.
Data extraction and relevant information sought

The results of the meta-analysis of aggregate data presented in table 2 are based on 33 trials; in the other tables, however, more studies and patients are shown because the two trials with three arms were split into two parts in which two different treatments were compared with the same control group. ${ }^{339}$

In a qualitative review of published studies it was recently documented that in many trials some patients had been excluded from the final analysis. ${ }^{51}$ We therefore tried to contact all investigators to analyse the whole original population enrolled into the trials. In 25/33 trials information on all randomised patients was retrieved according to the treatment arm to which they were originally allocated, allowing an "intention to treat" analysis. This, however, proved impossible in the trials of Finch et al, ${ }^{24}$ Rocha et al, ${ }^{29}$ and Verwaest et $\mathrm{al}^{33}$ for respiratory tract infections and those of Lenhart et $\mathrm{al}^{27}$ Georges et al, ${ }^{38}$ Wiener et al, ${ }^{44}$ and Laggner et $\mathrm{al}^{48}$ for infections and mortality.

Data on key variables relevant for this review were available from published reports. For 30 studies published figures were integrated with the following

Table 2 General characteristics of randomised clinical trials included in meta-analysis. Data were aggregate or for individual patients or both. End points were respiratory tract infection or mortality or both

\begin{tabular}{|c|c|c|c|c|c|c|c|c|}
\hline \multirow[b]{2}{*}{ Study name } & \multicolumn{2}{|l|}{ Type of treatment } & \multirow{2}{*}{$\begin{array}{l}\text { Mean age } \\
\text { (years) }\end{array}$} & \multirow{2}{*}{$\begin{array}{c}\text { Trauma } \\
\text { patients (\%) }\end{array}$} & \multirow{2}{*}{$\begin{array}{c}\text { Surgical } \\
\text { patients (\%) }\end{array}$} & \multirow{2}{*}{$\begin{array}{c}\text { Medical } \\
\text { patients (\%) }\end{array}$} & \multirow[b]{2}{*}{ Type of data } & \multirow[b]{2}{*}{ End points } \\
\hline & Topical & Systemic & & & & & & \\
\hline Abele-Horn et al ${ }^{19}$ & Polymyxin, tobramycin, amphotericin & Cefotaxime & 41.5 & 84 & 16 & 0 & Aggregate & Both \\
\hline Aerdts et $\mathrm{al}^{20}$ & Polymyxin, norfloxacin, amphotericin & Ceftriaxone & 46.7 & 34 & 26 & 40 & Both & Both \\
\hline Blair et $\mathrm{al}^{21}$ & Polymyxin, tobramycin, amphotericin & Ceftriaxone & 47.6 & 40 & 46 & 14 & Both & Both \\
\hline Boland et $\mathrm{al}^{22}$ & Polymyxin, tobramycin, nystatin & Ceftriaxone & 33.9 & 100 & 0 & 0 & Both & Both \\
\hline Brun-Buisson et a $\left.\right|^{35}$ & Polymyxin, neomycin, nalidixic acid & None & 59.0 & 2 & 23 & 75 & Both & Both \\
\hline Cerra et $\mathrm{al}^{36}$ & Norfloxacin, nystatin & None & 63.5 & 4 & 96 & 0 & Aggregate & Mortality \\
\hline Ferrer et al ${ }^{45}$ & Polymyxin, tobramycin, amphotericin & Ceftriaxone & 61.0 & 20 & 14 & 66 & Both & Both \\
\hline Finch et $\mathrm{al}^{24}$ & Polymyxin, gentamicin, amphotericin & Ceftriaxone & 59.2 & 4 & 37 & 59 & Both & Both \\
\hline Gastinne et al ${ }^{37}$ & Tobramycin, amphotericin, polymyxin & & 55.0 & 15 & 13 & 72 & Both & Both \\
\hline Gaussorgues et al ${ }^{46}$ & $\begin{array}{l}\text { Polymyxin, gentamicin, vancomycin, } \\
\text { amphotericin }\end{array}$ & Not specified & 57.0 & 17 & 0 & 83 & Aggregate & Mortality \\
\hline Georges et a $\left.\right|^{38}$ & Polymyxin, netilmicin, amphotericin & None & 32.3 & 100 & 0 & 0 & Both & Both \\
\hline Hammond et al ${ }^{47}$ & Polymyxin, tobramycin, amphotericin & Ceftriaxone & 43.3 & 31 & 14 & 55 & Both & Both \\
\hline Jacobs et $\mathrm{a}^{25}$ & Polymyxin, tobramycin, amphotericin & Ceftriaxone & 51.5 & 18 & 57 & 25 & Aggregate & Both \\
\hline Kerver et $\mathrm{al}^{26}$ & Polymyxin, tobramycin, amphotericin & Ceftriaxone & 55.6 & 28 & 60 & 12 & Aggregate & Both \\
\hline Korinek et $\mathrm{al}^{39}$ & $\begin{array}{l}\text { Polymyxin, tobramycin, amphotericin, } \\
\text { vancomycin }\end{array}$ & None & 45.0 & 50 & 50 & 0 & Both & Both \\
\hline Laggner et al ${ }^{48}$ & Gentamicin, amphotericin & Not specified & 53.8 & 2 & 10 & 88 & Both & Both \\
\hline Lenhart et $\mathrm{al}^{27}$ & Polymyxin, gentamicin & Ciprofloxacin & \multicolumn{4}{|c|}{ Information not available } & Aggregate & Mortality \\
\hline Lingnau et al ${ }^{49}$ & $\begin{array}{l}\text { 1: Polymyxin, tobramycin, amphotericin } \\
\text { 2: Polymyxin, ciprofloxacin, amphotericin }\end{array}$ & Ciprofloxacin & 38.0 & 100 & 0 & 0 & Both & Both \\
\hline Palomar et al ${ }^{28}$ & Polymyxin, tobramycin, amphotericin & Ceftriaxone & 45.5 & 50 & 10 & 40 & Both & Both \\
\hline Pugin et al ${ }^{40}$ & Polymyxin, vancomycin, neomicin & None & 45.5 & 56 & 33 & 11 & Both & Both \\
\hline Quinio et al ${ }^{41}$ & Polymyxin, gentamicin, amphotericin & None & 34.6 & 98 & 0 & 2 & Both & Both \\
\hline Rocha et al ${ }^{29}$ & Polymyxin, tobramycin, amphotericin & Ceftriaxone & 43.5 & 68 & 4 & 28 & Both & Both \\
\hline Rodriguez-Roldan et al ${ }^{42}$ & $\begin{array}{l}\text { Polymyxin, tobramycin/netilmicin, } \\
\text { amphotericin }\end{array}$ & None & 51.3 & 42 & 19 & 39 & Both & Both \\
\hline Sanchez-Garcia et al ${ }^{30}$ & Polymyxin, gentamicin, amphotericin & Ceftriaxone & 54.4 & 18 & 12 & 70 & Both & Both \\
\hline Stoutenbeek et $\mathrm{al}^{3}$ & Polymyxin, tobramycin, amphotericin & Ceftriaxone & 40.4 & 100 & 0 & 0 & Both & Both \\
\hline Stoutenbeek et a $\left.\right|^{31}$ & Polymyxin, tobramycin, amphotericin & Ceftriaxone & 39.8 & 100 & 0 & 0 & Both & Both \\
\hline Verwaest et $\mathrm{a}^{33}$ & $\begin{array}{l}\text { 1: Ofloxacin, amphotericin } \\
\text { 2: Polymyxin, tobramycin, amphotericin }\end{array}$ & $\begin{array}{l}\text { 1: Ofloxacin } \\
\text { 2: Ceftriaxone }\end{array}$ & 55.8 & 23 & 67 & 10 & Both & Both \\
\hline Wiener et $\mathrm{a}^{44}$ & Polymyxin, gentamicin, nystatin & None & \multicolumn{4}{|c|}{ Information not available } & Aggregate & Both \\
\hline Winter et al ${ }^{34}$ & Polymyxin, tobramycin, amphotericin & Ceftazidime & 59.2 & 13 & 47 & 40 & Both & Both \\
\hline
\end{tabular}




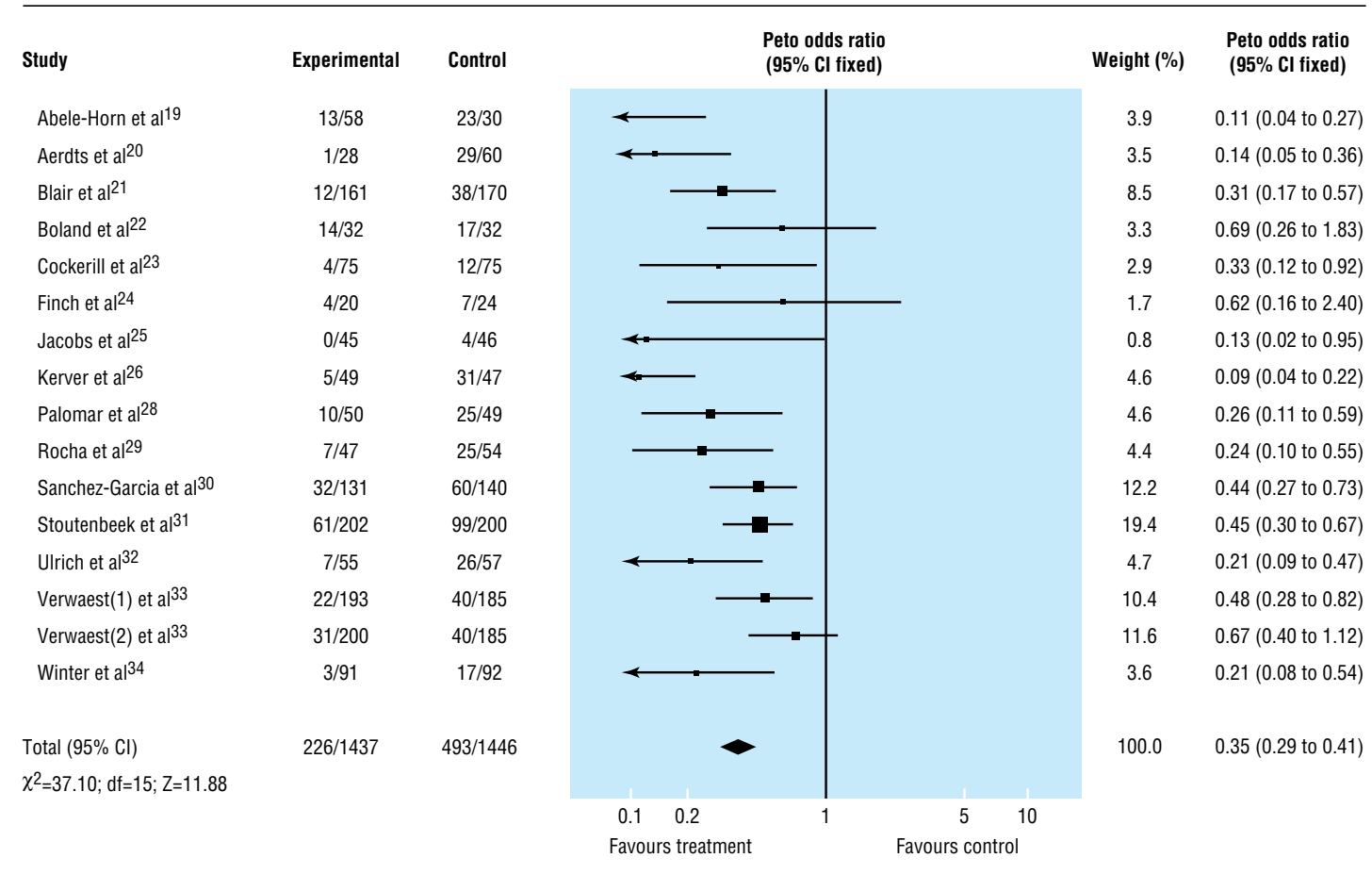

Fig 1 Meta-analysis of aggregate data. Effect of combination of topical and systemic antibiotics as prophylaxis for respiratory tract infections in patients in intensive care units

information that we obtained, in a standardised format, directly through personal contacts with study investigators: number of patients and their treatment allocation; method of randomisation and use of blinding techniques; type of comparison (type and dose of antibiotic); number of patients with at least one respiratory infection by treatment arm; number of deaths by treatment arm; and number of excluded patients, and number of respiratory infections and deaths among them.

To perform a meta-analysis on data from individual patients we sought the following information for each randomised subject: treatment arm; date of birth; sex; date of admission to intensive care unit; date of randomisation; type of diagnostic category (medical, surgical, trauma); severity score (simplified acute physiology score (SAPS)), acute physiological and chronic health evaluation (APACHE), and injury severity score (ISS) for trauma patients; systemic antibiotic treatment in the first 3 days; respiratory infections; vital status at discharge from intensive care; vital status at last follow up; and inclusion or exclusion and reason(s) for exclusion.

To explore whether the trials for which we obtained data on individual patients differed from all the trials we compared the results of pooled estimates of treatment effects on respiratory infections and mortality in the two datasets.

\section{Quality assessment of studies}

Study quality was assessed by looking at methods of randomisation (blind versus open) and use of blinding techniques (double blind versus unblind studies). The randomisation procedure was classified as blind when it was done by telephone through a pharmacy or a central office or by using sealed envelopes. It was classi- fied as open when it was done with a computer generated list directly managed by study investigators or when patients were allocated by odd-even number or other types of open lists.

The assignment of a study to a double blind or unblind category was according to what was reported by the authors. No attempt was made to measure the extent to which studies that were defined double blind kept their masked nature during the study.

\section{Outcome measures and statistical analysis}

Two main outcome measures were considered: respiratory tract infections and overall mortality. No restriction was made on type of infection considered and on diagnostic criteria for infection chosen by the trialists. Both tracheobronchitis and pneumonia were acceptable. Both primary (diagnosed within 48 hours after admission) and acquired (diagnosed after 48 hours after admission) infections were considered, even if we used data on acquired infections when information on both was available. Mortality was evaluated at hospital discharge, if this information was available, otherwise mortality in the intensive care unit was considered.

All patient records, for both aggregated and individual data, were converted to an agreed format and the following checks (performed by CL and SP) run on each dataset: simple checks of missing values; no duplicate patient records; treatment group assigned and survival status; range of prognostic variables; and checks for random allocation. For trials for which data on individual patients were available we constructed a plot of cumulative proportion of patients per arm versus time of randomisation for each study to check for major unbalances in the sequence of randomisation. 
In the analysis of data on individual patients we classified patients into three diagnostic categories: medical, surgical, and trauma. For classification of severity we relied on the APACHE II score in most cases; in seven trials for which the SAPS score was reported, ${ }^{24} 323537394145$ we transformed it into APACHE II using the following algorithm: APACHE $\mathrm{II}=-1.24+1.484 *(\mathrm{SAPS}) .^{52}$ Patients were grouped into three mutually exclusive classes within groups defined by the main diagnostic categories (medical, surgical, trauma) according to severity of disease. APACHE II cut off points were chosen to define low or medium or high severity with reference to the "expected mortality rate" $(<10 \%, 10-60 \%,>60 \%) .^{53}$

In addition to odds ratios of each outcome in each trial, computed with the fixed effects model (Peto method) ${ }^{54}$ we estimated the number of patients in intensive care who would need to be treated to prevent one infection and one death. The calculation was based on the median rates of infections and deaths in untreated controls and the common odds ratio for all trials.

We carried out two prespecified subgroup analyses on the basis of quality criteria within the above mentioned two main groups of trials: quality of randomisation procedures (blind versus open) and blinding of patients and doctors to allocated treatment (double blind versus unblind). For analyses on data on individual patients odds ratios, stratified by prognostic factor, were calculated with the fixed effects model.

\section{Results}

Information from 33 trials that between 1984 and 1996 enrolled a total of 5727 patients was the base for the aggregate data meta-analysis (table 2). Data on individual patients were obtained from 25/33 trials including 4343/5727 (76\%) patients.

\section{Respiratory tract infections}

Evaluation from meta-analysis of aggregate data

Overall, results from 30 trials including 4898 patients were available for the analysis of the effects of different types of antibiotic prophylaxis on respiratory tract infections: 1184 patients developed one or more infections (S Jacobs and M Zuleika, personal communication). ${ }^{19-26}$ 28-35 $37-45$ 47-50

The prevalence of respiratory infections was $16 \%$ among treated patients and 36\% among controls in trials that used a combination of topical plus systemic antibiotics and $18 \%$ and $28 \%$, respectively, in trials that tested the effectiveness of topical prophylaxis alone. Overall, the odds ratio was lower than unity in all but two comparisons ${ }^{44}{ }^{49}$ and reached conventional significance $(\mathrm{P}<0.05)$ in $21 / 32$ comparisons.

The results indicated a strong protective effect of the combination of topical and systemic treatment (odds ratio $0.35 ; 95 \%$ confidence interval 0.29 to 0.41 ) (fig 1). A clear though less extreme protection was also seen when treatment effect was explored in trials that tested topical antibiotics $(0.56$; 0.46 to 0.68$)$ (fig 2$)$.

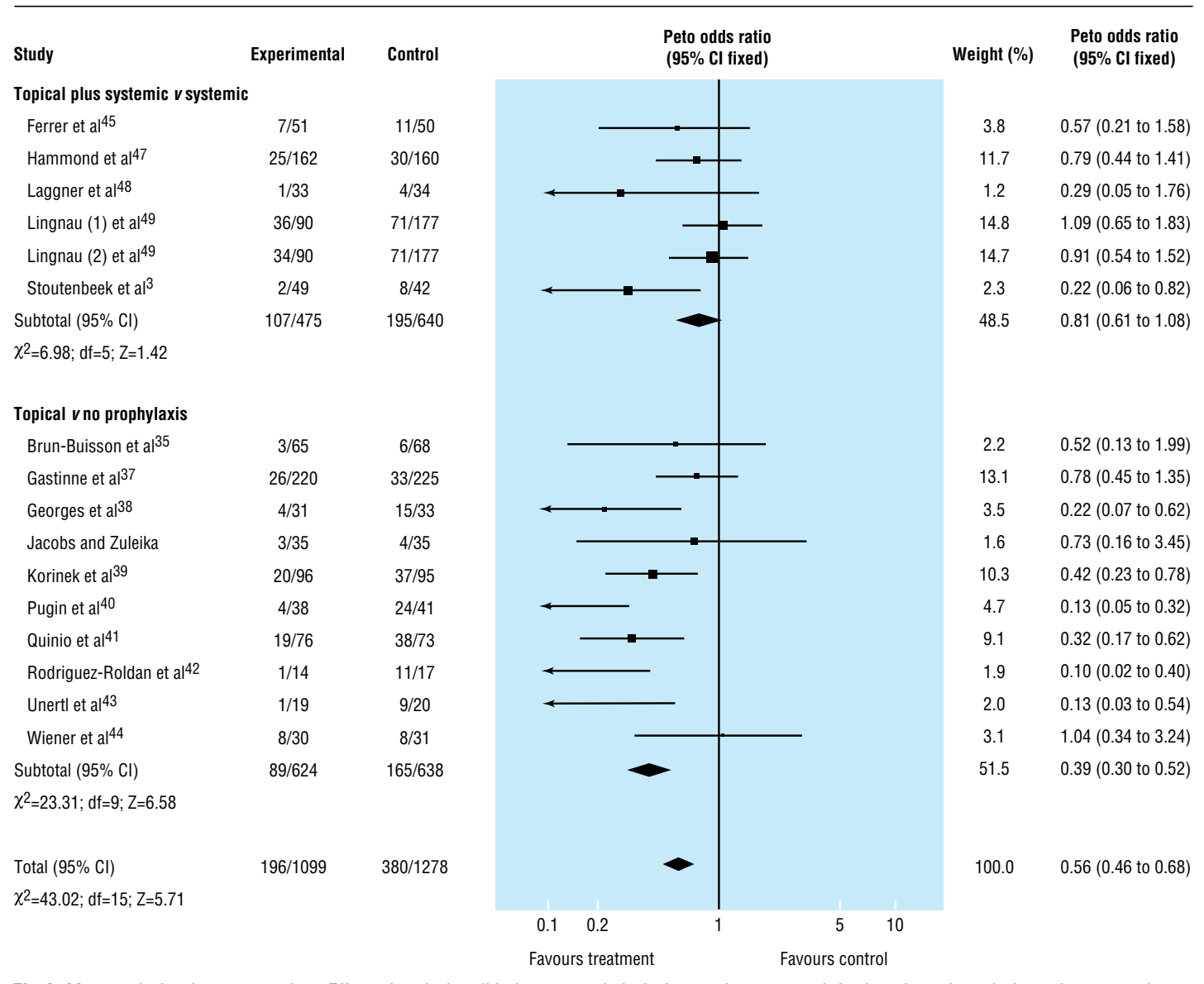

Fig 2 Meta-analysis of aggregate data. Effect of topical antibiotics as prophylaxis for respiratory tract infections in patients in intensive care units 
Table 3 Meta-analysis of data from individual patients. Effect of combination of topical and systemic antibiotics as prophylaxis for respiratory tract infections in patients in intensive care

\begin{tabular}{|c|c|c|c|c|}
\hline APACHE II scores & No of studies & No treated & No of controls & Odds ratio $(95 \% \mathrm{CI})$ \\
\hline \multicolumn{5}{|l|}{ Medical patients } \\
\hline $0-14$ & 10 & $10 / 67$ & $23 / 76$ & $0.37(0.16$ to 0.87$)$ \\
\hline $15-29$ & 10 & $14 / 155$ & $53 / 180$ & $0.28(0.16$ to 0.48$)$ \\
\hline$\geqslant 30$ & 10 & $7 / 54$ & $12 / 52$ & 0.57 (0.20 to 1.69) \\
\hline Total & & $31 / 276$ & $88 / 308$ & $0.33(0.22$ to 0.51$)$ \\
\hline \multicolumn{5}{|l|}{ Surgical patients } \\
\hline $0-14$ & 9 & $15 / 166$ & $24 / 142$ & $0.47(0.23$ to 0.94$)$ \\
\hline $15-29$ & 9 & $36 / 299$ & $70 / 309$ & $0.51(0.33$ to 0.78$)$ \\
\hline$\geqslant 30$ & 9 & $4 / 22$ & $6 / 26$ & 0.87 (0.21 to 3.64$)$ \\
\hline Total & & $55 / 487$ & $100 / 477$ & $0.51(0.36$ to 0.73$)$ \\
\hline \multicolumn{5}{|l|}{ Trauma patients } \\
\hline $0-14$ & 11 & $54 / 269$ & $116 / 294$ & 0.40 (0.28 to 0.58$)$ \\
\hline 15-29 & 12 & $59 / 258$ & $108 / 249$ & 0.37 (0.25 to 0.54$)$ \\
\hline$\geqslant 30$ & 12 & $5 / 13$ & $4 / 10$ & 0.07 (0.01 to 1.63) \\
\hline Total & & $118 / 540$ & $228 / 553$ & 0.38 (0.29 to 0.50$)$ \\
\hline Overall & & $204 / 1303$ & $476 / 1338$ & 0.40 (0.33 to 0.49$)$ \\
\hline
\end{tabular}

Table 4 Meta-analysis of data from individual patients. Effect of topical antibiotics as prophylaxis for respiratory tract infections in patients in intensive care

\begin{tabular}{|c|c|c|c|c|}
\hline APACHE II scores & No of studies & No treated & No of controls & Odds ratio $(95 \% \mathrm{CI})$ \\
\hline \multicolumn{5}{|l|}{ Medical patients } \\
\hline $0-14$ & 8 & $11 / 108$ & $17 / 117$ & 0.75 (0.34 to 1.67$)$ \\
\hline $15-29$ & 8 & $17 / 205$ & $43 / 232$ & $0.44(0.25$ to 0.77$)$ \\
\hline$\geqslant 30$ & 9 & $1 / 29$ & $4 / 23$ & 1.03 (0.06 to 16.69$)$ \\
\hline Total & & $29 / 342$ & $64 / 372$ & $0.54(0.34$ to 0.84$)$ \\
\hline \multicolumn{5}{|l|}{ Surgical patients } \\
\hline $0-14$ & 8 & $8 / 48$ & $13 / 57$ & 0.52 (0.17 to 1.53$)$ \\
\hline $15-29$ & 9 & $15 / 64$ & $17 / 63$ & 0.84 (0.35 to 1.99$)$ \\
\hline$\geqslant 30$ & 9 & $3 / 6$ & $0 / 4$ & 12.18 (0.55 to 270.15$)$ \\
\hline$\overline{\text { Total }}$ & & $26 / 118$ & $30 / 124$ & $0.79(0.41$ to 1.53$)$ \\
\hline \multicolumn{5}{|l|}{ Trauma patients } \\
\hline $0-14$ & 12 & $52 / 238$ & $103 / 303$ & 0.59 (0.40 to 0.88$)$ \\
\hline $15-29$ & 11 & $77 / 231$ & $148 / 312$ & 0.59 (0.41 to 0.85$)$ \\
\hline$\geqslant 30$ & 12 & $4 / 8$ & $6 / 12$ & 5.29 (0.31 to 89.62$)$ \\
\hline Total & & $133 / 477$ & $257 / 627$ & 0.60 (0.46 to 0.79$)$ \\
\hline Overall & & $188 / 937$ & $351 / 1123$ & $0.61(0.49$ to 0.75$)$ \\
\hline
\end{tabular}

Table 5 Comparison of results of randomised controlled trials according to availability of data from individual patients for prophylaxis with topical and systemic antibiotics and topical antibiotics only

\begin{tabular}{|c|c|c|c|c|}
\hline \multirow[b]{2}{*}{ End points and dataset used } & \multicolumn{2}{|c|}{ Topical plus systemic } & \multicolumn{2}{|c|}{ Topical alone } \\
\hline & $\begin{array}{l}\text { No of } \\
\text { trials }\end{array}$ & $\begin{array}{l}\text { Odds ratio } \\
(95 \% \mathrm{Cl})\end{array}$ & $\begin{array}{l}\text { No of } \\
\text { trials }\end{array}$ & $\begin{array}{l}\text { Odds ratio } \\
(95 \% \mathrm{Cl})\end{array}$ \\
\hline \multicolumn{5}{|l|}{ Mortality } \\
\hline Aggregate and individual data & 12 & 0.86 (0.72 to 1.02$)$ & 13 & $1.03(0.84$ to 1.26$)$ \\
\hline Aggregate data only & 3 & $0.61(0.44$ to 0.86$)$ & 4 & 0.93 (0.57 to 1.52$)$ \\
\hline \multicolumn{5}{|l|}{ Respiratory tract infection } \\
\hline Aggregate and individual data & 12 & 0.39 (0.32 to 0.47$)$ & 13 & $0.57(0.47$ to 0.70$)$ \\
\hline Aggregate data only & 2 & $0.10(0.05$ to 0.21$)$ & 2 & $0.47(0.19$ to 1.13$)$ \\
\hline
\end{tabular}

These results suggest that 5 (4 to 5 ) and 9 (7 to 13) patients would need to be treated to prevent one infection, depending on whether a combination of topical and systemic drugs or a topical antibiotic only is tested. This assumes the median values of $44 \%$ and $32 \%$ for baseline risk, respectively, as seen among control patients.

The effect of the quality of randomisation could meaningfully be explored only among trials that tested the relative effectiveness of topical antibiotic agents (given that all but two trials of the topical plus systemic group had blind randomisation): trials with blind randomisation showed a greater effect $(0.51 ; 0.40$ to 0.66$)$ compared with those in which the procedure was open $(0.66 ; 0.48$ to 0.91$)$. Results from double blind trials did not differ from those obtained in unblind studies.

\section{Evaluation from meta-analysis of data from individual patients}

The results from the 25 studies for which data were provided by the trialist are reported in tables 3 and 4 (S Jacobs and $\mathrm{M}$ Zuleika, personal communication). ${ }^{20-24} 28-35$ 37-42 45 47-50 Odds ratios and relative confidence intervals are presented within specific groups of diagnostic category and severity score. The effect of the treatment on infections is shown for both types of treatment protocols-that is, topical plus systemic $(0.40 ; 0.33$ to 0.49$)$ and topical alone $(0.61 ; 0.49$ to $0.75)$. The results seem more pronounced, however, in trials in which the combination was used.

The widespread belief that the treatment is more effective in patients with intermediate severity scores (that is, APACHE II score 15-29) and less effective among "medical" patients was not supported by the data from trials that tested the topical and systemic combination. The extent of the treatment effect was quite consistent across disease categories and severity groups. Data from trials that tested topical antibiotics are more difficult to interpret because of the small number of patients in the highest APACHE II category-that is, $\geqslant 30$.

Overall, these results did not differ substantially from those obtained by pooling data from trials for which data on individual patients were not available (table 5), suggesting that no bias was introduced by lack of data provided by study investigators.

\section{Mortality}

Evaluation from meta-analysis of aggregate data

A total of 1515 deaths occurred in the 33 trials with 5727 patients available for analysis (S Jacobs and M Zuleika, personal communication) ${ }^{19-50}$ The mortality was $24 \%$ in treated patients and $30 \%$ in controls for trials that tested a combination of topical plus systemic antibiotics and 26\% in control and treated patients for trials that tested the effectiveness of topical treatment. The odds ratio was lower than unity in 23/35 comparisons but reached significance in only two trials ${ }^{27}{ }^{31}$; no trial suggested a significant harmful effect of antibiotic prophylaxis. Results indicate a significant reduction in mortality attributable to the use of a combination of topical and systemic treatment $(0.80 ; 0.69$ to 0.93$)$ (fig 3 ). Twenty three patients (14 to 68 ) would need to be treated to prevent one death (if we assume a median baseline risk of $29 \%$ among control patients). No effect was seen when trials that tested topical antibiotics alone were analysed (1.01; 0.84 to 1.22 ) (fig 4).

While analyses by quality of randomisation did not affect the results, reduction in mortality among trials that tested a combination of topical and systemic antibiotics was greater in trials that used a double blind design $(0.63 ; 0.48$ to 0.83$)$ compared with unblind studies $(0.90 ; 0.74$ to 1.08$)$. 


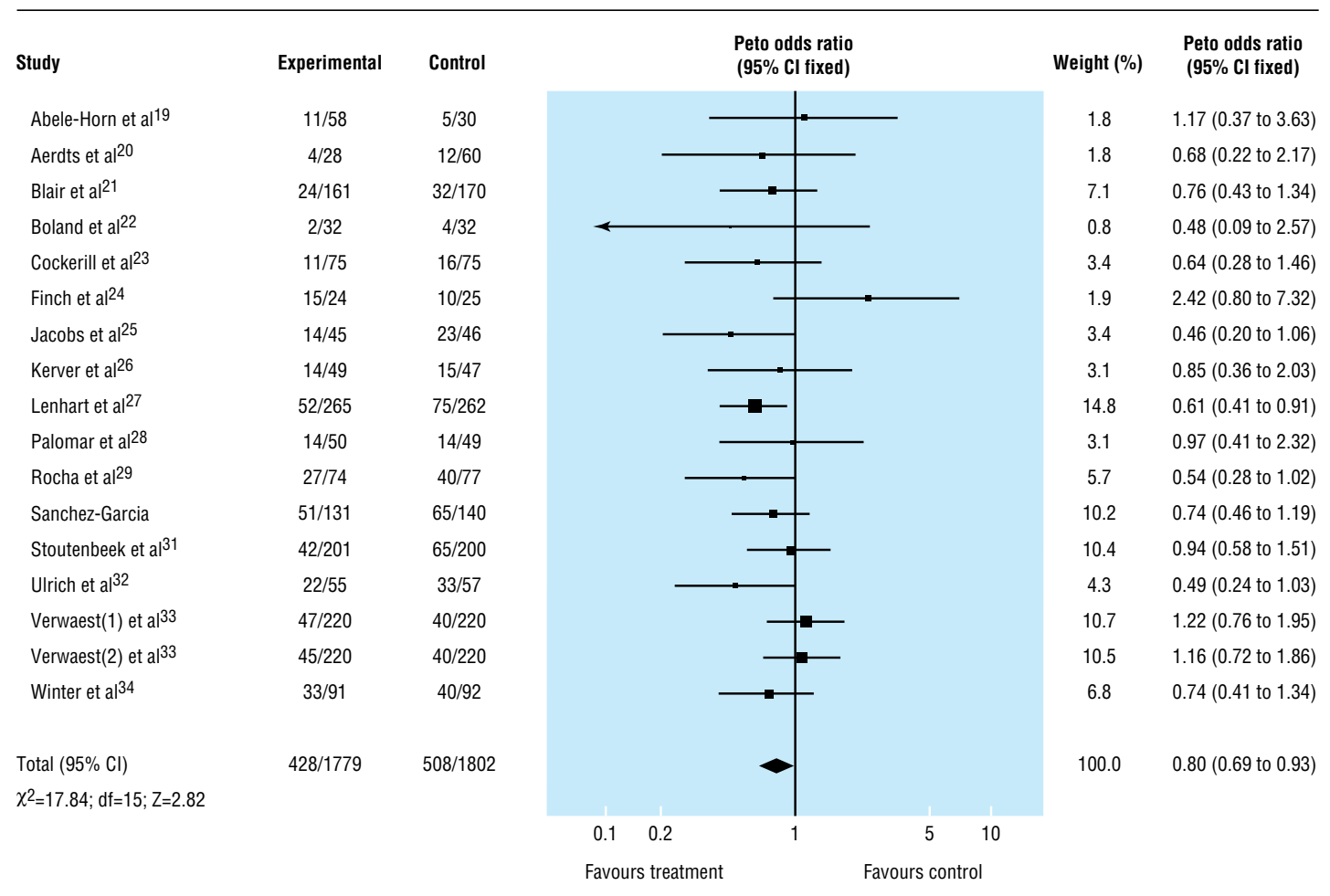

Fig 3 Meta-analysis of aggregate data. Effect of combination of topical and systemic antibiotics on mortality in patients in intensive care units

Evaluation from meta-analysis of data from individual patients

Results from 25 studies are reported in table 6 and 7 (S Jacobs and M Zuleika, personal communication). ${ }^{20-24}$ 28-35 37-42 45 $47-50$ Odds ratios with their relative confidence intervals are presented within specific groups of diagnostic categories and severity scores. Similarly to the results derived from the corresponding aggregate data analysis, a significant reduction in overall mortality was observed for trials that tested a combination of topical and systemic antibiotics $(0.79$; 0.65 to 0.97 ) but not from studies that tested topical drugs alone (1.02; 0.81 to 1.30$)$. Treatment effect did not vary substantially by main diagnostic category.

Overall, these results did not differ substantially from those obtained by pooling data from trials for which individual patient data were available (table 5).

\section{Discussion}

\section{Effectiveness of antibiotic prophylaxis}

Since its introduction as a method designed to prevent infection in critically ill patients the effectiveness of antibiotic prophylaxis has remained controversial. ${ }^{3}$ The lack of standard protocols and insufficient numbers of patients have made it difficult to derive meaningful conclusions from individual randomised controlled trials. Despite initial enthusiasm after results from early uncontrolled studies and initial trials, antibiotic prophylaxis-as tested in available trials-is not widely used in intensive care units. The concern about the risk of long term emergence of antibiotic resistance and of increasing costs dominates in recent American documents based on expert opinions on prevention of infections such as the Guidelines for
Prevention of Nosocomial Pneumonia recently published by the Centers for Disease Control and Prevention ${ }^{55}$ and the consensus statement of the American Thoracic Society on Hospital-Acquired Pneumonia in Adults. ${ }^{56} \mathrm{~A}$ conservative attitude in introducing a new treatment into practice is understandable as long as doubts exist about its efficacy. In fact studies on prevention of ventilator associated pneumonia in patients in intensive care units are complex because patients are heterogeneous, diagnosis of pneumonia is controversial, and outcome depends on many factors. Although the ability of antibiotic prophylaxis to reduce respiratory tract infections emerged with remarkable consistency across individual trials, the effect on mortality was significant in only two. It was never fully realised that this was

Table 6 Meta-analysis of data from individual patients. Effect of combination of prophylactic topical and systemic antibiotics on mortality in patients in intensive care

\begin{tabular}{|c|c|c|c|c|}
\hline APACHE II score & No of studies & No treated & No of controls & Odds ratio $(95 \% \mathrm{Cl})$ \\
\hline \multicolumn{5}{|l|}{ Medical patients } \\
\hline$\overline{0-14}$ & 10 & $16 / 67$ & $15 / 76$ & 1.45 (0.63 to 3.36$)$ \\
\hline $15-29$ & 10 & $57 / 155$ & $77 / 180$ & 0.80 (0.50 to 1.29$)$ \\
\hline$\geqslant 30$ & 10 & $26 / 54$ & $26 / 52$ & 0.72 (0.32 to 1.63$)$ \\
\hline Total & & $99 / 276$ & $118 / 308$ & 0.88 (0.61 to 1.27$)$ \\
\hline \multicolumn{5}{|l|}{ Surgical patients } \\
\hline $0-14$ & 10 & $12 / 166$ & $20 / 142$ & 0.43 (0.21 to 0.92$)$ \\
\hline $15-29$ & 9 & $67 / 299$ & $76 / 309$ & 0.91 (0.61 to 1.34$)$ \\
\hline$\geqslant 30$ & 9 & $12 / 22$ & $21 / 26$ & 0.26 (0.06 to 1.20$)$ \\
\hline Total & & $91 / 487$ & $117 / 477$ & $0.73(0.52$ to 1.03$)$ \\
\hline \multicolumn{5}{|l|}{ Trauma patients } \\
\hline $0-14$ & 11 & $26 / 268$ & $35 / 294$ & 0.81 (0.48 to 1.39 ) \\
\hline$\overline{15-29}$ & 12 & $57 / 258$ & $65 / 249$ & 0.76 (0.49 to 1.16$)$ \\
\hline$\geqslant 30$ & 12 & $8 / 13$ & $5 / 10$ & 0.95 (0.08 to 10.93$)$ \\
\hline Total & & $91 / 539$ & $105 / 553$ & 0.78 (0.56 to 1.09$)$ \\
\hline Overall & & $281 / 1302$ & $340 / 1338$ & $0.79(0.65$ to 0.97$)$ \\
\hline
\end{tabular}




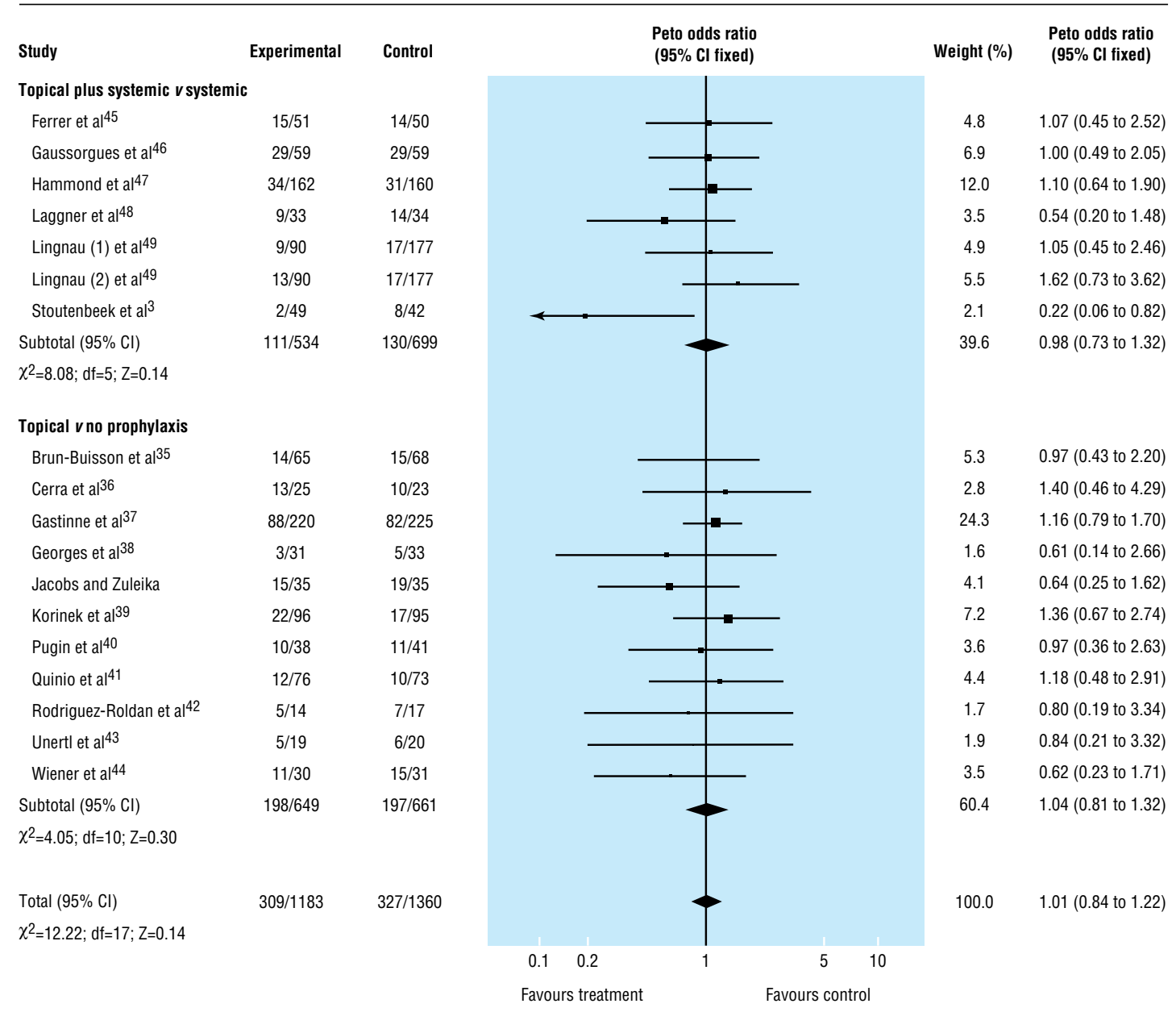

Fig 4 Meta-analysis of aggregate data. Effect of topical antibiotics on mortality in patients in intensive care units

probably because of the small sample sizes of individual studies and, possibly, the weak association between respiratory infections and mortality.

The meta-analysis reported here combines data across studies to estimate treatment effects with more precision than in a single study. ${ }^{57}$ Moreover, for a large proportion of trials data on individual patients were available, thus allowing a more refined analysis.

Table 7 Meta-analysis of data from individual patients. Effect of prophylactic topical antibiotics on mortality in patients in intensive care

\begin{tabular}{|c|c|c|c|c|}
\hline APACHE II score & No of studies & No treated & No of controls & Odds ratio $(95 \% \mathrm{Cl})$ \\
\hline \multicolumn{5}{|l|}{ Medical patients } \\
\hline $0-14$ & 8 & $18 / 108$ & $19 / 117$ & 0.99 (0.47 to 2.06$)$ \\
\hline $15-29$ & 6 & $77 / 205$ & $77 / 232$ & 1.08 (0.72 to 1.62$)$ \\
\hline$\geqslant 30$ & 9 & $15 / 29$ & $13 / 23$ & 1.09 (0.32 to 3.68$)$ \\
\hline Total & & $104 / 342$ & $109 / 372$ & 1.06 (0.75 to 1.49$)$ \\
\hline \multicolumn{5}{|l|}{ Surgical patients } \\
\hline $0-14$ & 8 & $10 / 48$ & $11 / 57$ & $1.25(0.44$ to 3.53$)$ \\
\hline $15-29$ & 9 & $18 / 64$ & $15 / 63$ & $1.18(0.52$ to 2.70$)$ \\
\hline$\geqslant 30$ & 9 & $2 / 6$ & $3 / 4$ & 0.46 (0.04 to 5.27$)$ \\
\hline Total & & $30 / 118$ & $29 / 124$ & 1.13 (0.61 to 2.12$)$ \\
\hline \multicolumn{5}{|l|}{ Trauma patients } \\
\hline $0-14$ & 12 & $17 / 238$ & $19 / 303$ & 1.20 (0.59 to 2.46$)$ \\
\hline $15-29$ & 11 & $36 / 231$ & $54 / 312$ & 0.84 (0.52 to 1.34$)$ \\
\hline$\geqslant 30$ & 12 & $4 / 8$ & $6 / 12$ & 1.17 (0.10 to 13.26$)$ \\
\hline Total & & $57 / 477$ & $79 / 627$ & 0.94 (0.64 to 1.39$)$ \\
\hline Overall & & $191 / 937$ & $217 / 1123$ & $1.02(0.81$ to 1.30$)$ \\
\hline
\end{tabular}

Compared with the five previously published metaanalyses we decided to analyse separately trials that tested a combination of topical and systemic antibiotics and those that tested topical antibiotics alone. Though there is no consensus on the best way to classify antibiotic prophylaxis regimens, ${ }^{56}$ it seemed rational to analyse these two groups of trials separately without combining all trials together. Our results confirm that both of these methods of prophylaxis have a strong protective effect on infections-with a more pronounced effect when patients are treated with the combination of topical plus systemic antibiotics. This effect was consistent for all subgroups of patients regardless of study design (blind or open randomisation, double blind or unblind studies). Overall, these results seem convincing even though it is acknowledged that no diagnostic test or procedure is ideal for diagnosing respiratory infections in patients in intensive care units.

The important new finding from this meta-analysis is that for prophylactic regimens that combine topical and systemic antibiotics there is also a relevant reduction of overall mortality.

Given the enthusiastic collaboration provided by most investigators and the efforts to include unpublished studies, it is unlikely that we have missed any important trials conducted so far. Moreover, as nearly all trials did not show significant reduction in mortality 
on their own, there is no good reason to believe that publication bias represents a major problem in this literature.

The inability to obtain data on individual patients from all trials is unlikely to have biased results of the meta-analysis of such data. As table 5 shows, results of trials for which we could not obtain information on individual patients were not substantially different from those with such data available. Further details on patients mix and treatments can be found in the version of this review available in the Cochrane Library. $^{58}$

\section{Insights from meta-analysis on data from individual patients}

A methodological strength of this review is the availability of data from individual patients for a large number of trials. Firstly, this allowed a comprehensive quality check of the data, which, by and large, confirmed the validity of the aggregate analysis. Secondly, the availability of data on individual patients permitted the identification of subgroups more likely to benefit from treatment. There is a widespread belief among clinicians that some patients may respond more favourably to the treatment. For example, patients categorised according to their underlying conditions as surgical or trauma patients and those with medium severity of illness scores are expected to respond more favourably to antibiotic prophylaxis than those labelled as medical patients or with low or high severity scores. Our subgroup analyses, however, do not support this view. The data in tables 3,4 , and 6 suggest that when the treatment works there is no difference in the size of treatment effect of the combined prophylaxis regimens among medical, surgical, and trauma patients within corresponding severity of disease.

Even though findings from subgroup analyses should always be treated with great caution these results could be important as they challenge a commonly held view among clinicians and provide useful information to orient the design of future trials. Indeed our failure to detect differences by diagnostic group could be because of lack of statistical power within subgroups. With the studies now available, however, claims suggesting that surgical and trauma patients $^{59}$ and patients with high APACHE scores ${ }^{6061}$ have better outcomes do not seem well founded and cannot be accepted.

\section{Implications for practice}

This systematic review indicates that a protocol that uses a combination of topical and systemic antibiotics reduces both the occurrence of respiratory tract infections and overall mortality. The effect of this intervention expressed in terms of patients needed to be treated to prevent one infection and one death is substantial-five and 23, respectively-and compares favourably with several interventions largely used in clinical practice. Though 8/16 trials used an identical regimen, including polymyxin, tobramycin, and amphotericin as the topical combination and cefotaxime as the systemic component, ${ }^{19} 2124-26282950$ this review does not allow a unique regimen to be recommended. The use of topical antibiotics alone, however, is not justified by available data.
Finally, it is important to bear in mind that given the lack of valid data no absolute conclusion can be drawn from this systematic review on the risk of antibiotic resistance. Future studies should look at this problem more carefully.

\section{Implications for research}

The number of trials examining antibiotic prophylaxis provides sufficient statistical power to detect a moderate but worthwhile effect of the treatment on mortality. ${ }^{5}$ According to this systematic review a protocol of a combination of topical and systemic antibiotics should be the standard against which new treatments are tested.

This meta-analysis could be criticised for the way trials have been grouped. We in fact assumed that the different drug combinations categorised as either topical plus systemic or topical only were equivalent. Although this may be inaccurate-as it may obscure the fact that the effective digestive decontamination achieved by different regimens can vary ${ }^{62-64}$ - we did not envision a viable alternative and preferred to be consistent with the other published meta-analyses. On the other hand, even if results of all available trials are combined-as has been done in other recent meta-analyses $^{6-8}$ - the reduction in mortality is still significant (odds ratio $0.88 ; 95 \%$ confidence interval 0.78 to 0.98 )

A logical next step for future trials would thus be the comparison of this protocol against a regimen of a systemic antibiotic agent only to see whether the topical component can be dropped. We have already identified six such trials ${ }^{31}{ }^{45-49}$ but the total number of patients so far enrolled (1056) is too small for us to be confident that the two treatments are really equally effective. If the hypothesis is therefore considered worth testing more and larger randomised controlled trials are warranted.

Trials of this kind, however, would not resolve the relevant issue of treatment induced resistance. To produce a satisfactory answer to this, studies with a different design would be necessary. Though a detailed discussion goes beyond the scope of this paper, studies in which the intensive care unit rather than the individual patient is the unit of randomisation and in which the occurrence of antibiotic resistance is monitored over a long period of time should be undertaken. One or more coordinated trials of this sort should be able to enrol a few thousands patients and should be designed in a pragmatic fashion concentrating on outcomes such as mortality, resistance, and costs. On the basis of our results it is not clear whether enrollment in these trials should be limited to specific categories of patients or should be open to all patients in intensive care. Given the uncertainty on this issue that stems from our analysis, trials with less strict eligibility criteria would be preferable. The growing collaboration among intensivists in the European Union Biomed Programme could provide a framework for designing and carrying out efficient studies aimed at settling this important research question.

The steering committee comprised DJ Cook (McMaster University Faculty of Health Sciences, Ontario), J Carlet (Hopital SaintJoseph, Paris), M Langer (Ospedale Maggiore Policlinico IRCCS, Milan), P Loirat (CMC FOCH Suresnes, Paris), and HFK Van Saene (University of Liverpool, Liverpool). The investiga- 
Key messages

- Over $40 \%$ of patients who need ventilation in intensive care develop respiratory tract infections and about 30\% may die in the units

- If the most effective antibiotic prophylaxis (that is, a protocol combining topical and systemic antibiotics) is used the incidence of respiratory tract infections can be reduced by $65 \%$ and total mortality by $20 \%$

- A regimen of topical antibiotics alone reduces respiratory tract infections but does not influence survival

- The concern that widespread antibiotic use may lead to resistance cannot be confirmed or ruled out by this review. Trials with different design are probably warranted to handle this question

- This important effect of antibiotic prophylaxis with a combination of topical and systemic antibiotics on survival should be considered by intensivists when treatment policies are designed

tors who were coauthors of this paper and provided data for meta-analysis of data from individual patients were SJA Aerdts (Sophia Hospital, Zwolle, the Netherlands); P Blair, BJ Rowlands, H Webb, and K Lowry (Royal Victoria Hospital, Belfast); JP Bowland, D Sadler, A Stewart, and J Pollock (Health Science Center Charlestone, West Virginia University); FR Cockerill and RI Thomson (Mayo Clinic, Rochester, Minnesota); M Ferrer and A Torres (Servei de Pneumologia, Hospital Clinic, Barcelona); RG Finch, P Tomlinson, and G Rocker (Nottingham City Hospital, Nottingham); H Gastinne (on behalf of the French Study Group on Selective Decontamination of the Digestive Tract); B Georges (Hôpital de Rangueil, Toulouse); JMJ Hammond and PD Potgieter (Groote Schuur Hospital, Cape Town); S Jacobs and M Zuleika (Riyadh Armed Forces Hospital, Riyadh); AM Korinek (Hôpital Pitié-Salpêtrière, Paris); AN Laggner (Vienna General Hospital, Vienna); W Lingnau (Leopold-FranzensUniversitat Innsbruck, Innsbruck); A Martinez-Pellus and J Rodriguez-Roldan (General Hospital, Murcia); M Palomar (Hospital Vall d'Hebron, Barcelona); J Pugin and P Suter (University Hospital, Geneva); C Martin, B Quinio, and J Albanese (Hôpital Nord, Marseilles); LA Rocha (Hospital Juan Canalejo, La Coruna); M Sanchez-Garcia (Hospital PPE Asturias, Alcala de Henares); CP Stoutenbeek (Academisch Ziekenhuis, Universiteit van Amsterdam, Amsterdam); C Ulrich and JE Harinck-De Weerd (Westeinde Hospital, The Hague); $\mathrm{J}$ Verhaegen and C Verwaest (University Hospital, Louvain); R Winter (Queen's Medical Centre University Hospital, Nottingham).

\section{Appendix}

\section{Studies excluded from this meta-analysis}

\begin{tabular}{ll} 
Author & Reason for exclusion \\
\hline Bion et al & Included selected population of patients undergoing liver transplant \\
\hline Flaherty et al $^{10}$ & Included selected population of cardiosurgical patients \\
\hline Hunefeldt et al $^{11}$ & Not properly randomised (that is, enrollment of consecutive patients) \\
\hline Lipman et al $^{12}$ & Not properly randomised (that is, enrollment of consecutive patients) \\
\hline Luiten et al $^{13}$ & $\begin{array}{l}\text { Included selected population of patients with pancreatitis characterised by } \\
\text { low percentage of admissions to intensive care unit randomised (that is, } \\
\text { enrollment of consecutive patients) }\end{array}$ \\
\hline Martinez-Pellus et al ${ }^{14}$ & Included selected population of cardiosurgical patients \\
\hline Rolando et al & Included selected population of patients with acute hepatic failure \\
\hline Schardey et al $\left.\right|^{16}$ & $\begin{array}{l}\text { Included selected population of patients undergoing gastric surgery and } \\
\text { characterised by low percentage of admissions to intensive care unit }\end{array}$ \\
\hline Smith et al ${ }^{17}$ & Included selected population of paediatric liver transplanted patients \\
\hline Tetteroo et al ${ }^{18}$ & $\begin{array}{l}\text { Included selected population of patients undergoing oesophageal } \\
\text { resection and characterised by short length of stay in intensive care unit }\end{array}$ \\
\hline
\end{tabular}

We thank L Brazzi (Ospedale Maggiore IRCCS, Milan) for his help and contribution in the earlier phases of this project, C Brun-Buisson (Hôpital Henry Monor, Creteil, Paris) for his useful comments and criticisms on several earlier drafts of this manuscript, and D Baxby (University of Liverpool, Liverpool) for editing an earlier draft of this manuscript. An earlier version of this paper won the Thomas C Chalmers Award at the fourth Cochrane Colloquium in Adelaide in October 1996.

Contributors: RD'A discussed core ideas of the project, participated in the design of the protocol for the meta-analysis of data from individual patients, had the main responsibility for data analysis and interpretation, and participated in writing the paper. SP discussed core ideas of the project, participated in the design of the protocol for the meta-analysis of data from individual patients, organised data collection, maintained contacts with the trialists checking data validity and accuracy, contributed to the interpretation of results, and participated in writing the paper. CL participated in the design of the protocol for the meta-analysis of data from individual patients, organised data collection, maintained contacts with the trialists checking data validity and accuracy, and contributed to the interpretation of results. VT discussed core ideas of the project, participated in the design of the protocol for the meta-analysis of data from individual patients, contributed to data analysis, and provided useful suggestions to the various drafts of the paper. AT designed and prepared the software for data management and helped with data analysis. AL initiated and coordinated the earlier phases of this research, discussed core ideas of the project, participated in the design of the protocol for the meta-analysis of data from individual patients, contributed to data analysis and interpretation, and had the main responsibility for writing the paper.

Funding: The meta-analysis of data from individual patients was supported by a grant from Hoechst Marion Roussel, Italy.

Conflict of Interest: None.

1 Fagon JY, Chastre J, Vuagnat A, Trouillet JL, Novara A, Gibert C. Nosocomial pneumonia and mortality among patients in intensive care unit. JAMA 1996;275:866-9.

2 Fagon JY, Chastre J, Hance AJ, Montravers P, Novara A, Gibert C. Nosocomial pneumonia in ventilated patients: a cohort study evaluating attributable mortality and hospital stay. Am J Med 1993:94:281-8.

3 Stoutenbeek CP, Van Saene HKF, Miranda DR, Zandstra, DF. The effect of selective decontamination of the digestive tract on colonization and infection rate in multiple trauma patients. Intensive Care Med 1984;10:185-92.

4 Vandenbroucke-Grauls CM, Vandenbroucke-Grauls JP. Effect of selective decontamination of the digestive tract on respiratory tract infections and mortality in intensive care unit. Lancet 1991;338:859-62.

5 SDD Trialists' Collaborative Group. Meta-analysis of randomised controlled trials of selective decontamination of the digestive tract. BMJ 1993;307:525-32.

6 Heyland DK, Cook DJ, Jaescher R, Griffith L, Lee HN, Guyatt GH. Selective decontamination of the digestive tract. An overview. Chest 1994;105:1221-9.

7 Hurley JC. Prophylaxis with enteral antibiotics in ventilated patients: selective decontamination or selective cross-infection? Antimicrob Agents Chemother 1995;39:941-7.

8 Kollef $\mathrm{M}$. The role of selective digestive tract decontamination on mortality and respiratory tract infections. A meta-analysis. Chest 1994;105:1101-8.

9 Bion JF, Badger I, Crosby HA, Hutchings P, Kong KL, Baker J, et al. Selective decontamination of the digestive tract reduces gram-negative pulmonary colonization but not systemic endotoxemia in patients undergoing elective liver transplantation. Crit Care Med 1994;22:40-9.

10 Flaherty J, Nathan C, Kabins SA, Weinstein RA. Pilot trial of selective decontamination for prevention of bacterial infection in an intensive care unit. J Infect Dis 1990;162:1393-7.

11 Hunefeld G. Klinische Studie zur selektiven Darmdekolonisation bei 204 langzeitbeatmeten abdominal und unfallchirurgischen Intensivpatienten. Anaesthesiologie und Reanimation 1989;14:131-53.

12 Lipman J, Klugman K, Luyt D, Kraus P, Litmanovitch M, Johnson D, et al. Unique trial design shows SDD to decrease and alter colonization of upper respiratory tract in a multidisciplinary ICU [abstract]. Crit Care Med 1994;141.

13 Luiten EJ, Hop WC, Lange JF, Bruining HA. Controlled clinical trial of selective decontamination for the treatment of severe acute pancreatitis. Ann Surg 1995;222:57-65.

14 Martinez-Pellus AE, Merino P, Bru M, Coneyero R, Seller G, Munoz C, et al. Can selective digestive decontamination avoid the endotoxemia and cytokine activation promoted by cardiopulmonary bypass? Crit Care Med 1993;2:1684-91.

15 Rolando N, Gimson A, Wade J, Philpott-Howard J, Casewell M, Williams R. Prospective controlled trial of selective parenteral and enteral antimicrobial regimen in fulminant hepatic failure. Hepatology 1993;17:196-201.

16 Schardey HM, Joosten U, Finke U, Staubach KH, Schauer R, Heiss A, et al. The prevention of anastomotic leakage after total gastrectomy with local decontamination: a prospective randomized, double-blind, placebocontrolled multicentre trial. Ann Surg 1997;225:172-80. 
17 Smith SD, Jackson RJ, Hannakanc J, Wadowsky RM, Tzakis AG, Rowe MI Selective decontamination in pediatric liver transplants. Randomised prospective study. Transplantation 1993;55:1306-9.

18 Tetteroo GWM, Wagenvoort JHT, Castelei A, Tilanus HW, Ince C, Bruining HA. Selective decontamination to reduce gram-negative colonisation and infections after oesophageal resection. Lancet 1990;335:704-7.

19 Abele-Horn M, Dauber A, Bauernfeind A, Russwurm W, SeyfarthMetzger I, Gleich P, et al. Decrease in nosocomial pneumonia in ventilated patients by selective oropharyngeal decontamination (SPO). Intensive Care Med 1997;23:187-95.

20 Aerdts SJA, van Dalen R, Clasener HAL, Festen J, van Lier HJJ, Vollaard EJ. Antibiotic prophylaxis of respiratory tract infection in mechanically ventilated patients. Chest 1991;100:783-91.

21 Blair P, Rowlands BJ, Lowry K, Webb H, Amstrong P, Smilie J. Selective decontamination of the digestive tract: a stratified, randomized, prospective study in a mixed intensive care unit. Surgery 1991;110:303-10.

22 Boland JP, Sadler DL, Stewart W, Wood DJ, Zerick W, Snodgrass KR Reduction of nosocomial respiratory tract infections in the multiple trauma patients requiring mechanical ventilation by selective parenteral and enteral antisepsis regimen (SPEAR) in the intensive care [abstract]. Seventeenth congress of chemotherapy, Berlin, 1991:No 0465.

23 Cockerill FR III, Muller SR, Anhalt JP, Marsh HM, Farnell MB, Mucha P, et al. Prevention of infection in critically ill patients by selective decontamination of the digestive tract. Ann Intern Med 1992;117:545-53.

24 Finch RG, Tomlinson P, Holliday M, Sole K, Stack C, Rocker G. Selective decontamination of the digestive tract (SDD) in the prevention of secondary sepsis in a medical/surgical intensive care unit [abstract]. Seventeenth international congress of chemotherapy, Berlin, 1991:No 0471.

25 Jacobs S, Foweraker JE, Roberts SE. Effectiveness of selective decontamination of the digestive tract (SDD) in an ICU with a policy encouraging a low gastric pH. Clin Intensive Med 1992;3:52-8.

26 Kerver AJH, Rommes JH, Mevissen-Verhage EAE, Hulstaert PF, Vos A, Verhoef J, et al. Prevention of colonization and infection in critically ill patients: A prospective randomized study. Crit Care Med 1988;16:1087.

27 Lenhart FP, Unertl K, Neeser G, Ruckdeschel G, Eckart J, Peter K. Selective decontamination (SDD) and sucralfate for prevention of acquired infections in intensive care [abstract]. Seventeenth international congress chemotherapy, Vienna, 1994:K101.

28 Palomar M, Alvarez-Lerma F, Jorda R, Bermejo B for the Catalan Study Group of Nosocomila Pneumonia Prevention. Prevention of nosocomial infection in mechanically ventilated patients: selective digestive decontamination versus sucralfate. Clin Intensive Care 1997;8:228-35.

9 Rocha LA, Martin MJ, Pita S, Paz J, Seco C, Margusino L, et al. Prevention of nosocomial infection in critically ill patients by selective decontamination of digestive tract. Intensive Care Med 1992;18:398-404

30 Sanchez-Garcia M, Cambronero JA, Lopez J, Cerda E, Rodriguez JM, Rubio J, et al. Reduced incidence of nosocomial pneumonia and shorter ICU stay in intubated patients with the use of selective decontamination of the digestive tract (SDD). A multicentric, double blind, placebocontrolled study [abstract]. European Congress on Intensive Care Medicine, Barcelona, 1992:No 0391.

31 Stoutenbeek CP, Van Saene HKF, Little RA, Whitehead A. The effect of selective decontamination of the digestive tract on mortality in multiple trauma patients. Ann Surg in press.

32 Ulrich C, Harinck-deWeerd JE, Bakker NC, Jacz K, Doornbos L, de Ridder VA. Selective decontamination of the digestive tract with norfloxacin in the prevention of ICU-acquired infections: a prospective randomized study. Intensive Care Med 1989;15:424-31.

33 Verwaest C, Verhaegen J, Ferdinande P, Schets M, Van der Berghe G, Verbist L, et al. Randomized, controlled trial of selective digestive decontamination in 600 mechanically ventilated patients in a multidisciplinary intensive care unit. Crit Care Med 1997;25:63-71.

34 Winter R, Humphreys H, Pick A, MacGowan AP, Willatts SM, Speller DCE. A controlled trials of selective decontamination of the digestive tract in intensive care and its effect on nosocomial infection. J Antimicrob Chemother 1992;30:73-87.

35 Brun-Buisson C, Legrand P, Rauss A, Richard C, Montravers F, Besbes M, et al. Intestinal decontamination for control of nosocomial multiresistant gram-negative bacilli. Ann Intern Med 1989;110:873-81.

36 Cerra FB, Maddaus MA, Dunn DL, Wells CL, Konstantinides NN Lehmann SL, et al. Selective gut decontamination reduces nosocomial infections and length of stay but not mortality or organ failure in surgical intensive care unit patients. Arch Surg 1992;127:163-9.

37 Gastinne H, Wolff M, Delatour F, Faurisson F, Chevret S. A controlled trial in intensive care units of selective decontamination of the digestive tract with nonabsorbable antibiotics. N Engl J Med 1992;326:594-9.

38 Georges B, Mazerolles M, Decun J-F, Rouge P, Pomies S, Cougot P, et al. Décontamination digestive sélective résultats d'une étude chez le polytraumatisé. Réanimation Soins Intensifs Médecin d'Urgence 1994:3: $621-7$

39 Korinek AM, Laisne MJ, Raskine L, Deroin V, Sanson-Lepors MJ. Selective decontamination of the digestive tract in neurosurgical care unit patients: a double blind, randomized, placebo-controlled study. Crit Care patients: a double blind,
Med 1993;21:1466-73.

40 Pugin J, Auckenthaler R, Lew DP, Suter PM. Oropharyngeal decontamination decreases incidence of ventilator-associated pneumonia. JAMA 1991;265:2704-10

41 Quinio B, Albanese J, Bues-Charbit M, Viviand X, Martin C. Selective decontamination of the digestive tract in multiple trauma patients: prospective, double blind, randomised, placebo-controlled study. Ches 1996;109:765-72.

42 Rodriguez-Roldan JM, Altuna-Cuesta A, Lopez A, Carrillo A, Garcia J, Leon J, et al. Prevention of nosocomial lung infection in ventilated patients: use of an antimicrobial pharyngeal nonabsorbable paste. Crit Care Med 1990;18:1239-42.
43 Unertl K, Ruckdeschel G, Selbmann HK, Jensen U, Forst H, Lenhart FP, et al. Prevention of colonization and respiratory infections in long term ventilated patients by local antimicrobial prophylaxis. Intensive Care Med 1987;13:106-13.

44 Wiener J, Itokazu G, Nothan C, Kabins SA, Weinstein RA. A randomized, double-blind, placebo-controlled trial of selective digestive decontamination in a medical-surgical intensive care unit. Clin Infect Dis 1995; 20:861-7.

45 Ferrer M, Torres A, Gonzales J, de la Bellacasa JP, El-Ebiary M, Roca M, et al. Utility of selective digestive decontamination in mechanically ventilated patients. Ann Intern Med 1994;120:389-95.

46 Gaussorgues P, Salord F, Sirodot M, Tigaud S, Cagnin S, Gerard M, et al Efficacité de la décontamination digestive sur la survenue des bactériémies nosocomiales chez les patients sous ventilation méchanique et recevant des betamimétiques. Réanimation Soins Intensifs Médecin d'Urgence 1991;7:169-74.

47 Hammond JMJ, Potgieter PD, Saunders GL, Forder AA. Double blind study of selective decontamination of the digestive tract in intensive tract. Lancet 1992;340:5-9.

48 Laggner AN, Tryba M, Georgopoulos A, Lenz K, Grimm G, Graninger W, et al. Oropharyngeal decontamination with gentamicin for long-term ventilated patients on stress ulcer prophylaxis with sucralfate? Wien Klin Wochenschr 1994;106:15-9.

49 Lingnau W, Berger J, Javorsky F, Lejeune P, Mutz N, Benzer H. Selective intestinal decontamination in multiple trauma patients: prospective, controlled trial.J Trauma 1997;42:687-94.

50 Stoutenbeek CP, Van Saene HKF, Zandstra DF. Prevention of multiple organ failure by selective decontamination of the digestive tract in multiple trauma patients. The immune consequences of trauma, shock and sepsis. In: Faist E, Baue AE, Schildberg FW, eds. Mechanisms and therapeutic approaches. Berlin: Pabst Science Publisher, 1996

51 Brazzi L, Liberati A. A review of design and conduct of the available studies on selective decontamination of the digestive tract (SDD). Réanimation Soins Intensifs Médecin d'Urgence 1992;1:501-7.

52 Gruppo Italiano Multicentrico di Ricerca in Terapia Intensiva (GIRTI II). Conversione tra APACHE II e SAPS. Minerva Anestesiol 1983;59:451-3.

53 Knaus WA, Draper EA, Wagner DP, Zimmerman JE. APACHE II: a severity of disease classification system. Crit Care Med 1985;13:818-29.

54 Yusuf S, Peto R, Lewis J, Collins R, Sleight P. Beta-blockade during and after myocardial infarction: an overview of the randomized trials. Prog Cardiovasc Dis 1985;27:335-71.

55 Tablan OC, Anderson LJ, Arden NH, Breiman RF, Butler JC, McNeil MM. Hospital Infection Control Practices Advisory Committee. Guidelines for prevention of nosocomial pneumonia. Infect Control Hosp Epidemiol $1994 ; 15: 587-627$

56 American Thoracic Society. Hospital-acquired pneumonia in adults: diagnosis, assessment of severity, initial antimicrobial therapy, and preventative strategies. A consensus statement. Am J Respir Crit Care Med 1995; 153:1711-25

57 Parmar MKB, Stewart LA, Altman DG. Meta-analysis of randomized trials: when the whole is more than just the sums of the parts. Br J Cancer 1996:74:496-501.

58 Liberati A, D'Amico R, Pifferi S, Leonetti C, Torri V, Brazzi L, et al. Antibiotic prophylaxis in adult patients treated in intensive care units. In: Douglas R, Bridges-Webb C, Glasziou P, Lozano J, Steinhoff M, Wang E, eds. Acute respiratory infections module, Cochrane Database of Systematic Reviews. The Cochrane Library. Cochrane Collaboration; Issue 3. Oxford: Update Software; 1997. Updated quarterly.

59 Nathens AB. Differential effect of decontamination of the digestive tract (SDD) on mortality in the surgical and medical ICU [abstract]. Shock 1997;suppl 7:697A.

60 Sun X, Wagner DP, Knaus WA. Does selective decontamination of the digestive tract reduce mortality for severely ill patients? Crit Care Med 1996;24:753-5.

61 Lecky PE, Little RE, Brennan P. The use and misuse of meta-analysis. J Accid Emerg Med 1996;13:373-8.

62 Mason CM, Dobard E, Summer WR, Nelson S. Intraportal lipopolysaccharide suppresses pulmonary antibacterial defense mechanisms.J Infect Dis 1997;176:1293-302

63 Van Saene JJM, Stoutenbeek CP, van Saene HFK, Matera G, Martinez-Pellus AE, Ramsay G. Reduction of the intestinal endotoxin pool by three different SDD regimens in human volunteers. J Endotoxin Res 1996;3:337-43.

64 Yong Ming Y, Lian-Rong L, Yan Y, Hua-Ping L, Jin-Song C, Zhi-Guo E et al. Influence of selective decontamination of the digestive tract on cellmediated immune function and bacteria/endotoxin translocation in thermally injured rats. J Trauma Injury Infect Crit Care 1997;42:1073-9.

(Accepted 16 December 1997)

\section{Endpiece}

\section{Alternative definitions}

Ambition: An overmastering desire to be vilified by enemies while living and made ridiculous by friends when dead.

Ambrose Bierce, The Cynic's Word Book (1906), subsequently titled The Devil's Dictionary 